\title{
DETERMINATION OF $\delta_{18}$ IN WATER FROM $\delta_{18}$ IN \\ EQUILIBRATED $\mathrm{CO}_{2}$ : INFLUENCE OF CHANGES IN \\ EXPERIMENTAL PARAMETERS ON THE EQUILIBRATION \\ PROCESS
}

\author{
VOLKER NESTLER and HARBANS LAL ARORA*
}

\begin{abstract}
The result of an isotopic exchange reaction is expressed in terms of the isotopic abundance ratios, the fractionation factor and the atom number ratio of the reactants. The general formula is applied to the $\mathrm{CO}_{2}-\mathrm{H}_{2} \mathrm{O}$ system and simplified by neglecting terms small in relation to the experimental crror. The influence of variations in the experimental parameters on the equilibrium is discussed. It is found that changes in temperature as well as atom number ratio will influence the equilibration process appreciably.
\end{abstract}

RESUMO O resultado de reação de troca isotópica é expresso em termos das razões de abundância isotópica, do fator de fracionamento e da razão entre os números de átomos dos reagentes. A fórmula geral é aplicada ao sistema $\mathrm{CO}_{2}-\mathrm{H}_{2} \mathrm{O}$ e simplificada desprezando-se termos pequenos comparados com os erros experimentais. A influência de variações nos parâmetros experimentais no equilíbrio é discutida. Demonstra-se que variações de temperatura, bem como da razão entre os números de átomos influenciam apreciavelmente o processo de equilíbrio.

INTRODUCTION The study of fluctuations in the concentration of stable isotopes ${ }^{18} \mathrm{O}$ and $\mathrm{D}$ in water by means of mass-spectrometric measurements is an efficient tool in applied fields such as surface and ground-water hydrology and plant physiology (see, for example, Bochin et al., 1972; Santiago et al., 1975; Salati etal., 1974; Gonfiantini et al., 1965; Mook, 1968; Dongmann, 1974; Wagener, 1975). However, water vapor cannot be investigated directly in the mass spectrometer due to the well known memory effect (Drost et al., 1974). In the usual procedure for the deuterium analysis, the water vapor is totally reduced over Uranium (Friedman and Hardcastle, 1970) to form essentially $\mathrm{UH}_{3}$ and $\mathrm{UDH}_{2}$. The hydrides decompose at high temperature and the $\mathrm{H}_{2}-\mathrm{HD}$-mixture is used for measurement. The Oxygen-18 analysis is done by isotopically equilibrating water with $\mathrm{CO}_{2}$, which is then investigated mass-spectrometrically.

The primary purpose of this work is to relate the isotopic composition of equilibrated $\mathrm{CO}_{2}$ to the relative ${ }^{18} \mathrm{O}$ content of the original water and to discuss the influence of variations in experimental conditions on the results of the equilibration process. However, since isotopic exchange reactions are also employed in equilibration processes of materials other than water, the general formula derived may be of some interest to other investigators in the field of stable isotope physics, as well.

General Formulation Consider an isotopic exchange reaction where the molecules $A$ and $B$ have one common element, existing in two stable isotopic forms 1 and 2.

$$
a A_{1}+b B_{2} \rightleftharpoons a A_{2}+b B_{1}
$$

Let $N_{T A}$ and $N_{T B}$ represent the total number of atoms of the common element in $A$ and $B$. If $N_{1 A}, N_{2 A}, N_{1 B}$ and $N_{2 B}$ designate the number of atoms of isotopes 1 and 2 in $A$

* Departamento de Física da Universidade Federal do Ceará, Caixa Postal 1262, Fortaleza, Ceará, Brasil 
and $B$ before the reaction starts and $N_{1 A}^{E}, N_{2 A}^{E}, N_{1 B}^{E}$ and $N_{2 B}^{E}$ the respective numbers after equilibrium has been reached, then

$$
\begin{aligned}
& N_{1 A}+N_{2 A}=N_{1 A}^{E}+N_{2 A}^{E}=N_{T A}, \\
& N_{1 B}+N_{2 B}=N_{1 B}^{E}+N_{2 B}^{E}=N_{T B} .
\end{aligned}
$$

Eqs. (2) and (3) imply that the chemical nature of the molecules did not change during the reaction.

The isotope abundance ratios $R$ are defined by

Eqs. (2)-(4) yield

$$
\begin{array}{ll}
R_{1 A}=\frac{N_{1 A}}{N_{2 A}}, & R_{1 B}=\frac{N_{1 B}}{N_{2 B}} ; \\
R_{1 A}^{E}=\frac{N_{1 A}^{E}}{N_{2 A}^{E}}, & R_{1 B}^{E}=\frac{N_{1 B}^{E}}{N_{2 B}^{E}} .
\end{array}
$$

$$
R_{1 A} N_{2 A}+R_{1 B} N_{2 B}=R_{1 A}^{E} N_{2 A}^{E}+R_{1 B}^{E} N_{2 B}^{E} \text {. }
$$

Defining $x$ to represent the ratio of the total number of atoms of the common element in $A$ and $B$ and using Eqs. (2)-(4)

$$
\begin{aligned}
x & =\frac{N_{T A}}{N_{T B}}, \\
& =\frac{N_{1 A}+N_{2 A}}{N_{1 B}+N_{2 B}}=\frac{N_{2 A}}{N_{2 B}}\left(\frac{1+R_{1 A}}{1+R_{1 B}}\right), \\
& =\frac{N_{2 A}^{E}}{N_{2 B}^{E}}\left(\frac{1+R_{1 A}^{E}}{1+R_{1 B}^{E}}\right) .
\end{aligned}
$$

Eqs. (5) and (6) can be combined to give

$$
\frac{N_{2 B}}{N_{2 B}^{E}}\left(R_{1 B}+x R_{1 A}\left(\frac{1+R_{1 B}}{1+R_{1 A}}\right)\right)=R_{1 B}^{E}+x R_{1 A}^{E}\left(\frac{1+R_{1 B}^{E}}{1+R_{1 A}^{E}}\right)
$$

using Eqs. (3) and (4):

$$
\frac{N_{2 B}}{N_{2 B}^{E}}=\frac{1+R_{1 B}^{E}}{1+R_{1 B}}
$$

The isotopic fractionation factor $\alpha$ is defined by

$$
\alpha=\frac{R_{1 B}^{E}}{R_{1 A}^{E}}
$$

Substituting Eqs. (8) and (9) into Eq. (7) and solving for $R_{1 A}$ yields

$$
R_{1 A}=\frac{R_{1 B}^{E}\left(\frac{1}{\alpha+R_{1 B}^{E}}+\frac{1}{x\left(1+R_{1 B}^{E}\right)}\right)-\frac{R_{1 B}}{x\left(1+R_{1 B}\right)}}{1-R_{1 B}^{E}\left(\frac{1}{\alpha+R_{1 B}^{E}}+\frac{1}{x\left(1+R_{1 B}^{E}\right)}\right)+\frac{R_{1 B}}{x\left(1+R_{1 B}\right)}} .
$$

Eq. (10) is the general expression for the isotope abundance ratio $R_{1 A}$ in $A$ in terms of the ratios $R_{1 B}$ and $R_{1 B}^{E}$ in $B$, the fractionation factor $\alpha$ and the atom number ratio $x$ between $A$ and $B$. In how far Eq. (10) can be simplified depends on the specific isotope exchange reac- 
tion and the values of the experimental parameters such as temperature (through $\alpha$ ) and $x$. In the following, one specific example of special interest will be treated.

EQUILIBRATION OF $\mathrm{CO}_{2}$ GAS WITH WATER SAMPLES FOR OXYGEN-18 ANALYSIS Consider the isotope equilibration between $\mathrm{H}_{2} \mathrm{O}$ and $\mathrm{CO}_{2}$, the isotopes ${ }^{18} \mathrm{O}$ and ${ }^{16} \mathrm{O}$ correspond to 1 and 2 respectively and $A$ and $B$ to water and $\mathrm{CO}_{2}$

$$
\begin{gathered}
\mathrm{H}_{2}^{18} \mathrm{O}+\mathrm{G}^{16} \mathrm{O}^{16} \mathrm{O} \rightleftharpoons \mathrm{H}_{2}^{16} \mathrm{O}+\mathrm{C}^{16} \mathrm{O}^{18} \mathrm{O} \\
R_{1 A}=R_{18}\left(\mathrm{H}_{2} \mathrm{O}\right) ; \quad R_{1 B}=R_{18}\left(\mathrm{CO}_{2}\right) ; \quad \alpha=\frac{R_{18}^{E}\left(\mathrm{CO}_{2}\right)}{R_{18}^{E}\left(\mathrm{H}_{2} \mathrm{O}\right)} .
\end{gathered}
$$

$R^{\prime} \mathrm{s}$ are of the order of $2 \times 10^{-3}, x \simeq 100$ and $\alpha \simeq 1.04$ at room temperature. $R^{\prime} \mathrm{s}$ relative to 1 (and $\alpha$ ) can be neglected and Eq. (10) reduces to

$$
R_{18}\left(\mathrm{H}_{2} \mathrm{O}\right)=R_{18}^{E}\left(\mathrm{CO}_{2}\right)\left(\frac{1}{\alpha}+\frac{1}{x}\right)-\frac{R_{18}\left(\mathrm{CO}_{2}\right)}{x} .
$$

$R_{18}\left(\mathrm{H}_{2} \mathrm{O}\right)$ of a water sample $(S A)$ is usually expressed in terms of the $\delta$ value relative to the respective ratio of the standard water $(S T)$ :

$$
\delta_{\mathrm{H}_{2} \mathrm{O}(S A)}^{\mathrm{H}_{2} \mathrm{O}(S T)}=\frac{R_{\mathrm{H}_{2} \mathrm{O}(S A)}}{R_{\mathrm{H}_{2} \mathrm{O}(S T)}}-1 .
$$

Inserting Eq. (12) into Eq. (13) and taking account of the possibility of different experimental conditions $(\alpha, x)$ and $\left(\alpha^{\prime}, x^{\prime}\right)$ when the two equilibration processes are performed, yields

$$
\delta_{\mathrm{H}_{2} \mathrm{O}(S A)}^{\mathrm{H}_{2} \mathrm{O}(\mathrm{S} T)}=\frac{R_{18\left(\mathrm{CO}_{2}(\mathrm{SA} A)\right)}^{E}\left(\frac{1}{\alpha}+\frac{1}{x}\right)-\frac{R_{18\left(\mathrm{CO}_{2}(T A)\right)}}{x}}{R_{18\left(\mathrm{CO}_{2}(\mathrm{SA} A)\right)}^{E}\left(\frac{1}{\alpha^{\prime}}+\frac{1}{x^{\prime}}\right)-\frac{R_{18\left(\mathrm{CO}_{2}(T A)\right)}}{x^{\prime}}}-1 .
$$

Expressing the isotope ratios of the right hand side of Eq. (14) in terms of $\delta^{\mathrm{CO}_{2}(\mathrm{ST})}$ results in where

$$
\delta_{\mathbf{H}_{2} \mathrm{O}(\mathrm{S} A)}^{\mathrm{H}_{2} \mathrm{O}(S T)}=\mathrm{P} \delta_{\mathrm{CO}_{2}(S A)}^{\mathrm{CO}_{2}(S T)}+Q
$$

$$
\begin{aligned}
& P=\frac{\frac{1}{\alpha}+\frac{1}{x}}{\frac{1}{\alpha^{\prime}}-\frac{1}{x^{\prime}} \beta} \\
& Q=\frac{\frac{1}{\alpha}-\frac{1}{x} \beta}{\frac{1}{\alpha^{\prime}}-\frac{1}{x^{\prime}} \beta}-1
\end{aligned}
$$

with Eq. (16), $\delta_{\mathrm{H}_{2} \mathrm{O}(\mathrm{S} A)}^{\mathrm{H}_{2} \mathrm{O}(\mathrm{ST})}$ can be calculated from the measurable quantities $\delta_{\mathrm{CO}_{2}(\mathrm{TA})}^{\mathrm{CO}_{2}(\mathrm{ST})}$ and $\delta_{\mathrm{CO}_{2}(\mathrm{SA} A)}^{\mathrm{CO}_{2}(\mathrm{ST})}$

These quantities stand for the $\delta$ values of tank $\mathrm{CO}_{2}$ and $\mathrm{CO}_{2}$ equilibrated with water sample, both with respect to $\mathrm{CO}_{2}$ equilibrated with standard water. $\alpha$ and $x$ refer to the sample, whereas $\alpha^{\prime}$ and $x^{\prime}$ correspond to the standard.

Using literature values (Dongmann, 1973) for the dependence of $\alpha$ on temperature, $\alpha$ can be expressed by the following linear relationship:

$$
\alpha(T)=1.0476-2.084 \times 10^{-4} T 5^{\circ} \mathrm{C} \leq T \leq 40^{\circ} \mathrm{C}
$$


Substituting Eq. (18) into Eqs. (16) and (17) yields

$$
\begin{aligned}
& P=\frac{\frac{1}{\frac{1.0476-2.084 \times 10^{-4} T}{1}+\frac{1}{x}}}{\frac{1}{1.0476-2.084 \times 10^{-4} T^{\prime}}-\frac{1}{x^{\prime}} \beta} \\
& Q=\frac{\frac{1}{\frac{1.0476-2.084 \times 10^{-4} T}{1}-\frac{1}{x} \beta}-1}{\frac{1}{1.0476-2.084 \times 10^{-4} T^{\prime}}-\frac{1}{x^{\prime}} \beta}
\end{aligned}
$$

Eqs. (19) and (20) can be further simplified by neglecting terms small in relation to the experimental error (usually \pm 0.0001 )

$$
\begin{gathered}
P=1+\frac{1.0476}{x}-2.084 \times 10^{-4} \frac{T}{x}+1.99 \times 10^{-4}\left(T-T^{\prime}\right)+\frac{1.0476}{x^{\prime}} \beta \\
Q=1.99 \times 10^{-4}\left(T-T^{\prime}\right)+\beta\left(1.0476\left(\frac{1}{x^{\prime}}-\frac{1}{x}\right)-2.084 \times 10^{-4}\left(\frac{T^{\prime}}{x^{\prime}}-\frac{T}{x}\right)\right)
\end{gathered}
$$

In order to evaluate $x$ it is necessary to look at the equilibration process more closely. The samples are prepared by freezing the water of volume $V_{\mathrm{H}_{2} \mathrm{O}}$, removing the residual gas and then adding $\mathrm{CO}_{2}$ up to a certain pressure $P_{\mathrm{CO}_{2}}$ (Drost et al., 1974). If the $\mathrm{CO}_{2}$ occupies the volume $V_{\mathrm{CO}_{2}}$, the O-atom ratio as defined by Eq. (6) id given by

where $|P|=$ Torr and $|T|={ }^{\circ} \mathrm{C}$.

$$
x=\frac{1722 \cdot V_{\mathrm{H}_{2} \mathrm{O}} \cdot(T+273)}{V_{\mathrm{CO}_{2}} \cdot P_{\mathrm{CO}_{2}}}
$$

During the equilibration process which usually lasts for about 20 hours, $\mathrm{CO}_{2}$ dissolves in water. If Eq. ( $\mathrm{R} 1)$ is to describe the reaction between $\mathrm{CO}_{2}$ in the gas phase and water in the liquid phase only, the $\mathrm{O}$-atom number ratio will increase to a value $x^{*}$, since the number density of gaseous $\mathrm{CO}_{2}$ decreases. From empirical values of solubility (Hildebrand, 1949), including the formation of $\mathrm{HCO}_{3}^{-}$ions, making a least square fit to the exponential dependence of solubility on temperature (assuming the Helmholtz free energy to be constant), and applying Henry's law, the solubility $S\left(\mathrm{~g} / \mathrm{cm}^{3}\right)$, within the temperature interval $0^{\circ} \mathrm{C}-30^{\circ} \mathrm{C}$ is given by

$$
S\left(T, P^{E}\right)=3.055 \times 10^{-10} \cdot P^{E} \cdot \exp \left(\frac{2612.4}{T+273}\right)
$$

where $P^{E}$ is the pressure at equilibrium in Torr and $T$ the temperature in ${ }^{\circ} \mathrm{C}$. From Eqs. (23) and (24), $x^{*}$ may be given the form

$$
x^{*}=x\left(1+4.304 \times 10^{-7} \cdot \frac{V_{\mathrm{H}_{2} \mathrm{O}}}{V_{\mathrm{CO}_{2}}} \cdot(T+273) \cdot \exp \left(\frac{2612.4}{T+273}\right)\right) .
$$

The effect of solubility on $x$ is quite pronounced as can be seen from the following example: $P=600$ Torr, $T=27^{\circ} \mathrm{C}, \frac{V_{\mathrm{CO}_{2}}}{V_{\mathrm{H}_{2} \mathrm{O}}}=9$, yield $x=95.7$ and $x^{*}=104$.

Tabs. I and II give an impression of the influence of changes in temperature, $T$, atom number ratio, $x$, and isotopic composition of $\operatorname{tank} \mathrm{CO}_{2}, \beta$, on the values of $P$ and $Q$ given by Eqs. (19) and (20) for $x^{\prime}=100, T^{\prime}=25^{\circ} \mathrm{C}$ and for two values of $\beta, \beta=-0.01$ and -0.015 . 
Table I - Values of $P$ and $Q$ for $x^{\prime}=100, T^{\prime}=25^{\circ} \mathrm{C}, \beta=-.01$ using Eqs. (19) and (20)

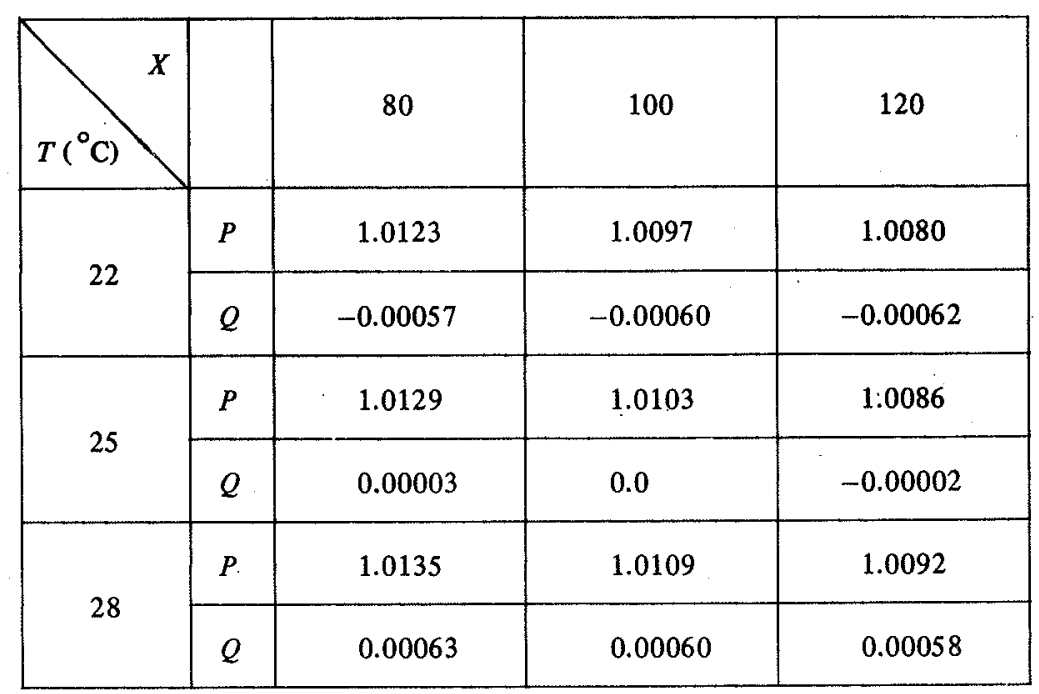

Table II - Values of $P$ and $Q$ for $x^{\prime}=100, T^{\prime}=25^{\circ} \mathrm{C}, \beta=-.015$ using Eqs. (19) and (20)

\begin{tabular}{|c|c|c|c|c|}
\hline \multirow{2}{*}{$T\left({ }^{\circ} \mathrm{C}\right)$} & & 80 & 100 & 120 \\
\hline \multirow{2}{*}{22} & & & & \\
\cline { 2 - 5 } & $Q$ & -0.00056 & -0.00060 & -0.00063 \\
\hline \multirow{2}{*}{25} & $P$ & 1.0129 & 1.0103 & 1.0085 \\
\cline { 2 - 5 } & $Q$ & 0.00004 & 0.0 & -0.00003 \\
\hline \multirow{2}{*}{28} & $P$ & 1.0135 & 1.0109 & 1.0091 \\
\cline { 2 - 5 } & $Q$ & 0.00064 & 0.00060 & 0.00058 \\
\hline
\end{tabular}

Discussion and Conclusions 1. Eq. (15) gives the $\delta$ value of ${ }^{18} \mathrm{O}$ in a water sample relative to standard water in terms of measurable quantities:

$\delta_{\mathrm{CO}_{2}(S A)}^{\mathrm{CO}_{2}(S T)}, \delta_{\mathrm{CO}_{2}(T A)}^{\mathrm{CO}_{2}(S T)} ; T, T^{\prime} ; x$ and $x^{\prime}$. The expression is very general as it includes explicitly the influence of variations in the experimental parameters.

It should be pointed out that Eq. (5) of Craig (Craig, 1957) relates the measured ${ }^{18} \mathrm{O}$ enrichment of $\mathrm{CO}_{2}$ equilibrated with the water sample (whose ${ }^{18} \mathrm{O}$ concentration has been slightly changed by the added $\mathrm{CO}_{2}$ ) to the ${ }^{18} \mathrm{O}$ enrichment of $\mathrm{CO}_{2}$ in equilibrium 
with the original water sample. This equation can be derived from Eq. (12) of the present work by expressing the results in terms of $\delta^{\prime}$ s and recognizing that $\delta$ in Graig's work is given by

$$
\delta=\left(1+\delta_{\mathbf{H}_{2} \mathbf{O}(\mathbf{S} A)}^{\mathrm{H}_{2} \mathbf{O}(S T)}\right) \alpha-1 .
$$

2. The isotopic composition of $\mathrm{CO}_{2}$ (for example, commercial $\mathrm{CO}_{2}$ ) may not be identical in the two equilibration processes. Tabs. I and II show that the effect of such changes $(\beta=-0.01$ to $\beta=-0.015)$ on $\delta_{\mathrm{H}_{2} \mathrm{O}(S A)}^{\mathrm{H}_{2} \mathrm{O}(S T)}$ is less than the analytical error $( \pm 0.0001)$. Hence such effects may be neglected.

3. The atomic number ratio may change due to volume differences in the vessels employed for equilibration, dissolution of a fraction of $\mathrm{CO}_{2}$ in water, existence of water vapor and errors in the determination of $P_{\mathrm{CO}_{2}}, V_{\mathrm{CO}_{2}}$ and $V_{\mathrm{H}_{2} \mathrm{O}}$, which quantities are used in calculating $x$ [Eq. (23)]. Tabs. I and II demonstrate that, for constant $T$, the changes in $Q$ are negligible but those in $P$ are important. Consequently, variations in $x$ should be considered in the determination of $\delta_{\mathrm{II}_{2} \mathrm{O}(\mathrm{SA})}^{\mathrm{H}_{2} \mathrm{O}(\mathrm{ST})}$.

4. Fluctuations in temperature influence both $P$ and $Q$ strongly. It is imperative therefore that the temperature is the same in both equilibration processes. Furthermore, since the room temperature will usually be different from the temperature of the equilibration bath, $\mathrm{CO}_{2}$ gas should be separated from the water immediately after removing the equilibration vessel from the bath. This is usually done by freezing the water (containing dissolved $\mathrm{CO}_{2}$ ) in a dry-ice-alcohol bath. This process, even though very fast, may influence the isotopic equilibrium reached in the temperature bath because both $\alpha$ (due to its dependence on the temperature) and $x$ (due to the increase in solubility of $\mathrm{CO}_{2}$ in water) may change noticeably. It might be of practical importance, therefore, to study the shift in isotopic equilibrium as a function of temperature difference and freezing-out time. It should be pointed out that the method of sample preparation varies somewhat from one laboratory to the other. Consequently, it is necessary to apply distinct corrections in each specific case. Thus, for example, some of the laboratories do not follow the usual procedure discussed above, but draw a sample from the water vapour- $\mathrm{CO}_{2}$ mixture in order to minimize the effect of temperature on equilibrium. Other laboratories make use of two standards so that some corrections do not apply.

5. The value of $\alpha$ given in the literature (Dongmann, 1973) and used in the above calculations is supposed to correspond to reaction (R1) only (Craig, 1957). However, the measured $\alpha$ is the effective isotopic fractionation factor which is the net result of a number of exchange processes occuring in the $\mathrm{CO}_{2}$-water system :

$$
\begin{aligned}
& \mathrm{C}^{16} \mathrm{O}^{16} \mathrm{O}(G)+\mathrm{H}_{2}{ }^{18} \mathrm{O}(L) \rightleftharpoons \mathrm{C}^{16} \mathrm{O}^{18} \mathrm{O}(G)+\mathrm{H}_{2}{ }^{16} \mathrm{O}(L) \\
& \mathrm{C}^{16} \mathrm{O}^{18} \mathrm{O}(G) \rightleftharpoons \mathrm{C}^{16} \mathrm{O}^{16} \mathrm{O}(D) \\
& \mathrm{C}^{16} \mathrm{O}^{16} \mathrm{O}(D)+\mathrm{H}_{2}{ }^{18} \mathrm{O}(L) \rightleftharpoons \mathrm{C}^{16} \mathrm{O}^{18} \mathrm{O}(D)+\mathrm{H}_{2}{ }^{16} \mathrm{O}(L) \\
& \mathrm{C}^{16} \mathrm{O}^{16} \mathrm{O}(G)+\mathrm{H}_{2}{ }^{18} \mathrm{O}(V) \rightleftharpoons \mathrm{C}^{16} \mathrm{O}^{18} \mathrm{O}(G)+\mathrm{H}_{2}{ }^{16} \mathrm{O}(V)
\end{aligned}
$$

where $(G),(L),(D),(V)$ designate gas, liquid, dissolved and vapour respectively. Since the influence of the above reactions on the equilibration process would be a function of the solubility of $\mathrm{CO}_{2}$ in water and therefore on $x$, the effective $\alpha$ will not only depend on temperature but also on the volume ratio $V_{\mathrm{H}_{2} \mathrm{O}} / V_{\mathrm{CO}_{2}}$ with which the equilibration process was performed.

Acknowledgements One of the authors (H. L. A.) would like to thank the Brazilian Conselho Nacional de Desenvolvimento Científico e Tecnológico (CNPq) for partial financial assistence. 


\section{REFERENCES}

BOGHIN, N., DUMITRESGU, S., BRADLEY, E., FERONSKY, V. I., GONFINATINI, R., and PAYNE, B.R. - 1972 - Status and reasons for using isotope techniques in hydrology. In: Peaceful uses of Atomic Energy, UN, New York and IAEA, Wien, 14: 41 1-423

GRAIG, H. - 1957 - Isotopic standards for carbon and oxygen and correction factors for mass-spectrometric analysis of carbon dioxide. Geochim. Cosmochim. Acta 12: 133-149

DONGMANN, G. - $1973-$ Die $\mathrm{H}_{2}^{18} \mathrm{O}-$ Anreicherung in den Blättern transpirierender Pflanzen und ihre Bedeutung für die stationare ${ }^{18} \mathrm{O}$ - Uberhöhung in der Atmosfäre, Thesis, Technical University Aachen.

DONGMANN, G. - 1974 - The Contribution of land photosynthesis to the stationary enrichment of ${ }^{18} \mathrm{O}$ in the atmosphere. Radiation and Environm. Biophys. $11: 210-225$

DROST, W., MOSER, H., NEUMAIER, F., and RAUERT, W. - 1974 - Isotope methods in groundwater hydrology, Eurisotop Office, Information and Documentation Service. 176 pp.

FRIEDMAN, I., and HARDCASTLE, K. - 1970 - A new technique for pumping hydrogen gas. Geochim. Cosmochim. Acta 34: 125-126.

GONFIANTINI, R., GRATZUI, S., and TONGIORGI, E. - 1965 - Proc. Sym. Use Isotopes Radiation in Soil-Plant Nutrition Studies, Ankara. IAEA: 405-410.

HILDEBRAND, J. H. - 1949 - Principles of Chemistry. 5th ed. New York. The Macmillan Company. $446 \mathrm{pp}$

MOOK, W. G. - 1968 - Geochemistry of the Stable Carbon and Oxygen Isotopes of natural Waters in the Netherlands. Ph. D. Dissertation

SALATI, E., LEAL, J. M. and CAMPOS, M. M.-1974-Environmental isotopes used in a hydrogeological Study of Northeastern Brasil. In: Isotope Techniques in Groundwater Hydrology 1974. Vol. 1, IAEA, Wien: 259-283.

SANTIAGO, M. M. F., SALATI, E., and MATSUI, E. - 1975 - Fracionamento Isotópico da água $\left({ }^{18} \mathrm{O}\right.$ e $\left.\mathrm{D}\right)$ do açude Santo Antonio de Russas durante a evaporação. Rev. Bras. de Geociências 5 (2): 106-112.

WAGENER, K. - 1975 - Kinetic isotope effects of oxygen in photosynthesis and respiration. In: Physical and Chemical Sciences Research Report 1, Dahlem Workshop on the Nature of Seawater, 433-451 